Manuelle Medizin 2015 -53:325

DOI 10.1007/s00337-015-0047-x

Online publiziert: 10 . September 2015

(c) Springer-Verlag Berlin Heidelberg 2015

CrossMark

\author{
R. Kern \\ Hürm, Österreich
}

\title{
Univ.-Prof. Hans Tilscher zum 80. Geburtstag
}

Informationskurs und E1-Kurs im Kurzentrum Oberlaa bei Wien zu leiten. In der Folge durfte ich auch W1-, W2- und W3-Kurse leiten.

2005, anlässlich seiner Feier zum 70. Geburtstag in Pörtschach, spielte ich ein Lied von Anton Rubinstein auf der Geige (auch Hans Tilscher lernte als Kind Geige spielen). Da ich das Stück solo (meine Klavierbegleitung war ausgefallen) und in unmittelbarer Nähe von Hans vortrug, hatte ich den Geigenbogen wegen zittriger Hand nicht unter Kontrolle, sodass es recht jämmerlich klang.

Trotz allem bedankte sich Hans am nächsten Morgen beim Frühstück bei mir und summte die Melodie des Liedes. Es war dann 8 Jahre später, als er sich in der Bar des Hotels Werzer in Pörtschach zu uns setzte und diese Melodie (ich hatte sie längst vergessen) auf den Lippen hatte.

Aber nicht nur sein musikalisches Gedächtnis, sondern auch sein Geschichtswissen ist beeindruckend. Im September 2006, anlässlich eines Kongresses der DGMM in Potsdam, saß ich neben ihm im Autobus in Richtung Potsdamer Schloss Cecilienhof. Gleich einem Geschichtslehrer plauderte er über die Ursachen und Folgen der Potsdamer Konferenz 1945.

Eine besondere Ehre für mich ist sein Vertrauen in mich: Er sandte mich als seinen Vertreter im September 2005 nach London zur Generalversammlung der FIMM, außerdem übertrug er mir vor einigen Jahren die Leitung des Refresherkurses, den er bis dahin immer selbst leitete.

Die Lehre Hans Tilschers bereichert mein Arbeiten in der Allgemeinpraxis ungemein, ohne sie wäre ich nicht so mit Begeisterung dabei. Ich versuche, diesen
Funken der Begeisterung auf junge Kollegen in meinen Kursen überspringen zu lassen. Die Kursteilnehmer sehen am Ende dieser Kurse, inhaltlich von Hans Tilscher und Manfred Eder geprägt, welch ungemein wichtiges schulmedizinisches Wissen ihnen ohne diese Kurse entgangen wäre.

Jedes Jahr zum Kongress in Pörtschach bewundere ich seine geistigen Kapazitäten, sodass ich überzeugt bin, dass er noch sehr lange Kapitän auf unserem Boot der ÖÄGMM sein wird.

Dr. Rudolf Kern

Vizepräsident der ÖÄGMM

\section{Korrespondenzadresse}

\section{Dr. R. Kern}

Hürm 88, 3383 Hürm, Österreich rukake@gmx.at 